\title{
Historia de la Hacienda \\ Pública en Míchoacán, \\ 1786-1951. \\ Una historia larga
}

José Alfredo Uribe Salas

Universidad Michoacana de San Ni-

colás de Hidalgo. Facultad de Historia jausalas@gmail.com

El historiador Jorge Silva Riquer Reseña del libro de Jorge Silva Riquer (coordinador), Historia de la Hacienda es especialista en historia ecoPública en Michoacán, 1786-1951. Una historia larga. Morelia: Universidad Michoacana de San Nicolás de son ampliamente conocidas en la comunidad académica por sus aportaciones historiográficas. Ha Hidalgo, El Colegio de San Luis, 2015, publicado obras importantes como $259 \mathrm{pp}$. La administración de alcabalas y pulques de Michoacán, 1776-1821 (1993), La estructura y dinámica del comercio menudo en la ciudad de Valladolid, Michoacán, a fines del siglo XVIII (2007), El mercado regional de Michoacán y el mercado urbano de Valladolid, 1778-1809 (2008) y La producción y los precios agropecuarios en Michoacán en el siglo XVIII. El mercado regional colonial (2012).

La Historia de la Hacienda Pública en Michoacán, 1786-1951 abona a los estudios emprendidos hace más de dos décadas, ahora desde la perspectiva de esa añeja institución económica. El libro resulta de gran actualidad para reflexionar sobre las condiciones económicas y fiscales en las que vivieron y trabajaron nuestros tatarabuelos, bisabuelos, abuelos y padres. Nada más actual que conocer hoy en día el papel del Estado y de los gobernantes que administran los impuestos públicos; o los intereses de las empresas y los empresarios del campo y la ciudad, sean micro, pequeñas, medianas o grandes, tanto en la generación de riqueza como en su contribución al gasto público vía impuestos fiscales; o también, el papel de los contribuyentes físicos, etcétera. 
El libro, fruto de un esfuerzo colectivo, tiene diversas cualidades y aportaciones a esa reflexión y estudio de la realidad; destaca en principio el esfuerzo por repensar y posicionar la dimensión del pensamiento económico y hacendario en el centro del análisis histórico. Y aquí vale señalar el gran acierto para apuntalar la reflexión analítica sobre los postulados doctrinarios, las tradiciones y el cruce de influencias intelectuales recibidas y ejercidas, tanto como los procesos de trasferencia y difusión de ese pensamiento económico y fiscal a lo largo de la vida pública de Nueva España y México durante los siglos XVIII al XX.

También se plantea cómo la institución de la Hacienda Pública en los entornos colonial y republicano ha sido uno de los terrenos más proclives a la intervención de las autoridades en turno a través de la introducción de reformas con claros objetivos para obtener beneficios económicos y hasta políticos. Y finalmente, tanto el estudio del pensamiento económico-fiscal como el estudio de la acción político-hacendaria de los actores involucrados en cada tramo o coyuntura de su devenir se expresaron de manera diferente, y esas circunstancias produjeron en el escenario sociopolítico novohispano y mexicano posturas e intereses encontrados y conflictos de carácter político que exacerbaron las contradicciones del capitalismo.

Historia de la Hacienda Pública en Michoacán, coordinado por Jorge Silva Riquer, recoge tres trabajos extensos que abordan distintos aspectos de la historia de la fiscalidad con un enfoque tridimensional: colonialnacional-estatal; desde las Ordenanzas de Intendencia y la reforma fiscal borbónica hasta el establecimiento y evolución de la Hacienda pública, sus política fiscales, los mecanismos de recaudación y las resistencias fiscales por parte de las entidades federales, los ayuntamientos y sujetos contribuyentes.

A lo largo de sus páginas se descubren planteamientos, problemas, conceptos, conjeturas, datos, procedimientos y análisis de documentos que permiten a sus autores recuperar la enorme variedad, riqueza y problemática del pasado de la fiscalidad. El libro es producto de investigaciones serias, pues sus afirmaciones se basan siempre en información y análisis de documentos que atestiguan la complejidad del entramado de la historia de la hacienda pública en la transición de la economía colonial a otra de carácter nacional liberal, en el que se expone de manera amplia las políticas implementadas por los gobiernos nacionales y su correspondiente interpretación, instrumentalización y aplicación en los ámbitos de los estados que integraron en el siglo xIX la división jurídico-política de la República mexicana.

La originalidad del libro la encontramos en el abordaje de la fiscalidad desde lo regional y local, en el que participan como actores fundamenta- 
les las instituciones estatal y municipal de Michoacán, que sólo de manera parcial e insuficiente habían sido consideradas en los estudios de la historia de la hacienda pública nacional. Los autores proponen una nueva mirada a las reformas fiscales que se ensayaron entre 1786 y 1951, y sus impactos en el reordenamiento de la hacienda pública del estado de Michoacán en esa temporalidad.

El primer trabajo, "La Real Hacienda y la ordenanza de intendencia de 1786: ensayo sobre su estructura y funcionamiento a partir del caso de Valladolid de Michoacán, 1786-1820", de la autoría de Netzahualcóyotl Luis Gutiérrez Núñez, parte de un detallado estudio de la Real Hacienda y la Intendencia de Valladolid, su estructura y funcionamiento, que permite analizar la organización y el funcionamiento fiscal en la configuración jurisdiccional de su territorio (dinámica demográfica, económica y comercial) con reglamentos y procedimientos para la extracción impositiva.

Esa discusión se enmarca en dos ámbitos: en las reformas a las monarquías europeas y en la viabilidad del Estado monárquico absolutista e ilustrado español, con el propósito de hacer eficientes y eficaces sus políticas fiscales, y la concreción de las reformas en la reconfiguración fiscal de las intendencias a partir de 1786 y el incremento de los ingresos en las cajas reales. En ambos casos se estudian sus consecuencias en las transacciones atlánticas y sus impactos en la economía y en la población regional y local de la Intendencia de Valladolid. Se destacan en este sentido las resistencias y evasiones de las elites y de otros sectores económicos que vieron afectados sus intereses, que fueron acompañadas de prácticas ilegales, actividades ilícitas y acuerdos informales.

Ello permite entrever sus particularidades en la organización y reorganización política de los sujetos económicos y de las actividades productivas, las resistencias y evasiones, nuevos escenarios de negociación entre el centro y la periferia, y un cierto margen de autonomía fiscal regional que trajeron consigo las reformas borbónicas a los impuestos corporativos de la Real Hacienda. Pero también negociaciones y acuerdos en el proceso de transición hacia una República federal, la reorganización territorial de las nuevas jurisdicciones en el ámbito de los distritos y ayuntamientos, y los esquemas fiscales asociados a ellos.

El segundo bloque analítico lleva por título "La construcción de la Hacienda Pública en Michoacán, 1821-1896", de Jorge Silva Riquer, en el que se aborda las obligaciones que asume el recién inaugurado Estado nacional y las relaciones ambiguas y conflictivas entre la federación y las nuevas entidades jurídico-políticas en la administración de sus territorios y recursos entre 1821 y 1896 . Se destaca de manera singular el peso de los actores económicos locales en la interpretación de los reglamentos 
fiscales y su adaptación a las circunstancias y condiciones propias, a sus intereses y compromisos particulares, muy distintos y distantes de las necesidades del Estado. El autor analiza con rigor el debilitamiento de la Hacienda Pública a lo largo del siglo XIX, y señala que éste fue proporcional al bajo control en los mecanismos de recaudación de los impuestos, a su aplicación impositiva al consumo y a la ambigua autonomía fiscal que buscaban los actores locales, circunstancias que propiciarían una constante penuria del erario público en ese largo periodo.

El asunto de las alcabalas, un rubro importante de recaudación estatal, resistió pero también resintió los embates que buscaban su liquidación desde la reforma fiscal de 1877 hasta la de 1895. La Reforma a la Hacienda Pública de Michoacán en los años finales del siglo XIX concretó la separación entre los ingresos y los egresos, impuso una recaudación más eficiente con una base impositiva que se alejaba del consumo para introducir una tasa impositiva más cercana al concepto de renta, y la reducción de la deuda pública. Silva Riquer analiza, con series estadísticas, los cambios en la política fiscal estatal más acordes a las nuevas dinámicas económicas y comerciales, respaldadas éstas por nuevas y mayores inversiones productivas.

El tercer segmento, "Hacienda Pública y reforma fiscal en Michoacán, 1896-1951", de Abel Padilla Jacobo, abarca los años del porfirismo y las primeras décadas del México revolucionario y posrevolucionario. En él se estudia la modernización de la Hacienda Pública, la transición de la base impositiva sobre el consumo al impuesto sobre la renta, en el que se establece una nueva relación fiscal entre el gobierno estatal y los municipios, esbozada en la reforma fiscal de la década de 1870 por el gobierno federal influida por concepciones liberales y centralizadoras. El proceso de centralización de los asuntos fiscales pasó necesariamente por la Constitución de 1917, en que se dibujan nuevos escenarios impositivos sobre la propiedad inmueble, la producción y la circulación de mercancías, etcétera. La reconfiguración de las instituciones fiscales estatales y los nuevos esquemas de negociación con los Ayuntamientos y los actores económicos locales harían de la tierra el sustento impositivo del erario público. Aquí se analiza el papel del impuesto sobre la renta como un mecanismo de centralización federal que inhibiría el espíritu de autonomía fiscal practicado por las autoridades y actores locales a lo largo del siglo XIX.

El impuesto sobre la propiedad raíz definiría los encuentros y desencuentros entre la federación y las fuerzas estatales y municipales. La ampliación del gravamen a la propiedad y nuevos impuestos a la producción y circulación agrícola y agroindustrial conjugarían diversos escenarios jurídicos-administrativos: la actualización del catastro, el asunto fiscal de 
los ejidos, en un proceso más o menos confuso e inacabado en la repartición impositiva, y la premura por gravar actividades productivas que estaban dinamizando la economía regional.

La construcción de series numéricas sobre los impuestos directos e indirectos entre los años de finales del siglo XIX y la década de 1950 permite ver el comportamiento y los pormenores de las reformas de la Hacienda Pública y sus aspectos de modernización en los planos nacional, estatal y municipal. El estudio señala el fuerte componente centralizador de la federación sobre los intereses fiscales del estado y los municipios, que se traduciría en un nuevo pacto federal en materia fiscal-hacendaria.

Historia de la Hacienda Pública en Michoacán apunta cómo los intereses públicos y privados fueron dos elementos de importancia en la conformación del territorio, la propiedad, la política fiscal y la modernización de la estructura hacendaria entre finales del siglo XVIII y mediados del XX. El libro abona a esa mirada, a problematizar el contexto, el pensamiento económico y los esquemas y prácticas fiscales en la larga duración: 17861951. También viene a llenar un vacío con propuestas novedosas y la incorporación de fuentes no conocidas o poco trabajadas, pasando por la crítica de fuentes, la elaboración de series estadísticas de largo aliento y el análisis hermenéutico sobre los cambios y las permanencias que tuvieron lugar en las finanzas públicas de Michoacán. 